\title{
ADSORPTION OF AMMONIA IONS AND AMMONIUM FROM AQUEOUS SOLUTIONS ON MODIFIED ACTIVATED CARBONS
}

\author{
T. Lupashcu*, M. Ciobanu \\ Institute of Chemistry of the Academy of Sciences of Moldova \\ Email:lupascut@gmail.com
}

\begin{abstract}
The adsorption process of ammonia ions and ammonium from aqueous solutions on the intact activated carbon obtained from nutshells through activation with phosphoric acid and oxidized with $\mathrm{H}_{2} \mathrm{O}_{2}$ and later impregnated with salt containing $\mathrm{Co}^{2+}, \mathrm{Ag}^{+}, \mathrm{Ni}^{2+}, \mathrm{Cu}^{2+}$, has been investigated. The efficiency of ammonia ions and ammonium elimination from various water categories, using both activated carbon (the intact CAN-7 and CAN-7 oxidized with $\mathrm{H}_{2} \mathrm{O}_{2}$ and impregnated with $\mathrm{Co}^{2+}, \mathrm{Ag}^{+}, \mathrm{Ni}^{2+}, \mathrm{Cu}^{2+}$ ions) has been demonstrated.
\end{abstract}

Keywords: adsorption, ammonia ion, ammonia and activated carbon.

\section{Introduction}

Adsorption of ammonium vapors on activated carbons has been studied using adsorption technique [1-10] or those of calorimetry technique [11-14]. In literature, one can find few data regarding the adsorption of ammonia ions from aqueous solutions on modified activated carbons.

We have studied the adsorption of ammonia ions from aqueous solutions on activated carbons CAN-7 and CANO-7 obtained from nutshells, activated with phosphoric acid and oxidized with $\mathrm{H}_{2} \mathrm{O}_{2}$.

As the result of activated carbon CAN-7 oxidation, the content of acid functional groups has increased from 1.4 to $1.62 \mathrm{mg}$-echiv/g.

The oxidized activated carbons have been treated with aqueous solutions of $\mathrm{Co}^{2+}, \mathrm{Ag}^{+}, \mathrm{Ni}^{2+}$ and $\mathrm{Cu}^{2+}$ salts.

\section{Results and discussions}

The percentage of $\mathrm{NH}_{3}$ in the solutions formed from ammonium salts varies significantly depending on the solution's $\mathrm{pH}$ and temperature [15]. Analytical determination of $\mathrm{NH}_{4}^{+}$content [15] is actually reduced to the determination of ammonia ions and ammonium total quantity.

Fig. 1 shows the adsorption isotherms of $\mathrm{NH}_{4}^{+}$ions and $\mathrm{NH}_{3}$ from aqueous solutions on CAN-7, CANO-7 $+\mathrm{Co}^{2+}, \mathrm{CANO}-7+\mathrm{Cu}^{2+}, \mathrm{CANO}-7+\mathrm{Ag}^{+}, \mathrm{CANO}-7+\mathrm{Ni}^{2+}$ on initial $\mathrm{pH} 6,13$ and temperature $20^{\circ} \mathrm{C}$.

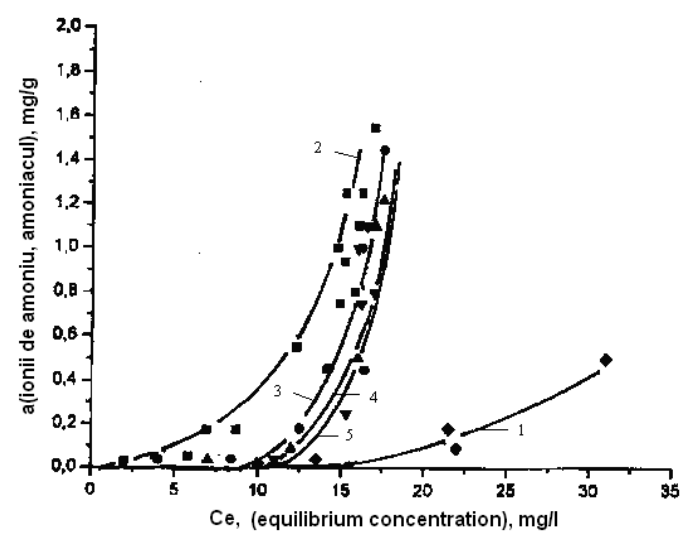

Fig.1. Adsorption isotherms of $\mathrm{NH}_{4}^{+}$ions and $\mathrm{NH}_{3}$ from aqueous solution on intact $\mathrm{CAN}-7$ (1), CANO-7 $+\mathrm{Co}^{2+}$

(2), $\mathrm{CANO}-7+\mathrm{Cu}^{2+}(3), \mathrm{CANO}-7+\mathrm{Ag}^{+}(4), \mathrm{CANO}-7+\mathrm{Ni}^{2+}(5)$ on initial $\mathrm{pH} \quad 6,13$ and temperature $20^{\circ} \mathrm{C}$.

Data shown in fig.1 demonstrate that the oxidation of activated carbon CAN-7, followed by impregnation with various metal cations, modify substantially both form of $\mathrm{NH}_{4}^{+}$and $\mathrm{NH}_{3}$ adsorption isotherms. Also the adsorption capacity of CAN-7 increases. It should be noted that impregnation of activated carbon CANO-7 with Co ${ }^{2+}$ greatly increases (compared with other samples of investigated activated carbons) the adsorption capacity of $\mathrm{NH}_{4}^{+}$ions and $\mathrm{NH}_{3}$. It is also worth mentioning that the content of metals in the samples of modified activated carbon is of: $\mathrm{Co}-0.2 \%$, $\mathrm{Ag}-1 \%, \mathrm{Ni}-0.04 \%, \mathrm{Cu}-0.16 \%$.

The high value of ammonia ions and ammonium adsorption on $\mathrm{CANO}-7+\mathrm{Co}^{2+}$ activated carbon samples can be explained by the increased capacity of $\mathrm{Co}^{2+}$ to form coordinative compounds with $\mathrm{NH}_{3}$. In the solution, $\mathrm{Co}^{2+}$ forms five coordinative compounds with $\mathrm{NH}_{3}$. For $\left[\mathrm{Co}\left(\mathrm{NH}_{3}\right)_{6}\right]^{2+} \mathrm{pK}_{1,2.3,4.5}=5,13 . \mathrm{K}_{1,2,3,4,5}=7,4 \cdot 10^{-6}[16]$. 
Fig. 2 shows the dependence of adsorption values of ammonia ions and of ammonium on the $\mathrm{pH}$ of equilibrium concentrations solutions on $\mathrm{CANO}-7+\mathrm{Co}^{2+}$ and $\mathrm{CAN}-7$ at $\mathrm{t}=20^{\circ} \mathrm{C}$.

The data show a considerable increase of adsorption values, starting with certain values of $\mathrm{pH}$. At relatively high values of $\mathrm{pH}$ (in the alkaline medium), the adsorption of ammonium formed in these conditions becomes significant.

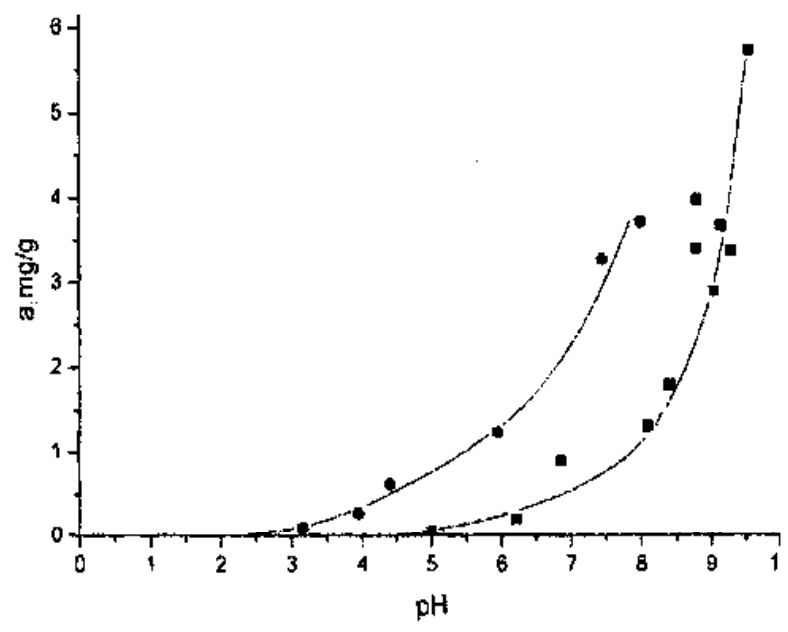

Fig.2. Dependence of adsorption $\mathrm{NH}_{3}$ and $\mathrm{NH}_{4}^{+}$ions upon the $\mathrm{pH}$ of equilibrium concentrations solutions on activated carbon $\mathrm{CAN}-7(\bullet)$ and $\mathrm{CANO}-7+\mathrm{Co}^{2+}(\boldsymbol{\bullet}) \cdot \mathrm{t}=20^{\circ} \mathrm{C}$.

It has been found [17] that ammonium is adsorbed on the carbon surface through chemosorption (fig.3).<smiles>Cc1c(C)c(C(N)=O)c(C(N)=O)c(C(N)=O)c1CC(C)C</smiles>

Fig. 3. Interaction of ammonium with the surface of the adsorbent [17].

The maximum value of ammonia ions adsorption on intact CAN-7 and CANO-7 $+\mathrm{Co}^{2+}$ activated carbon can be calculated on the basis of Dubinin-Serpinschi equation (DS-1) inferred for the process of water vapors adsorption on the active centers from the surface of the adsorbent. Its linear form has been utilized:

\section{$\mathrm{Ce} / \mathrm{Cs} / a=1 / a m C-1 / a m \mathrm{Ce} / \mathrm{Cs}$,}

where $\mathrm{Ce}$ is the equilibrium concentration of $\mathrm{NH}_{4}^{+}$and $\mathrm{NH}_{3}(\mathrm{mmol} / \mathrm{l})$; $\mathrm{Cs}$ is the solubility of $\mathrm{NH}_{3}(\mathrm{mmol} / \mathrm{l})$; $a$ is the adsorption value of $\mathrm{NH}_{4}^{+}$ions and $\mathrm{NH}_{3}(\mathrm{mmol} / \mathrm{g}$ ). Substitution, in equation DS-1, of P/Ps for Ce/Cs (to be applied in solutions) is, in our opinion, totally justified taking into consideration the applicability of Dubinin-Radushchievichi equation for solutions [18].

Fig. 4 shows the dependence $\mathrm{Ce} / \mathrm{Cs} / a$ on $\mathrm{Ce} / \mathrm{Cs}$ of the isotherm of ammonia ions and of the ammonium on intact CAN-7 (1) and CANO-7+ $\mathrm{Co}^{2+}$ activated carbon. 


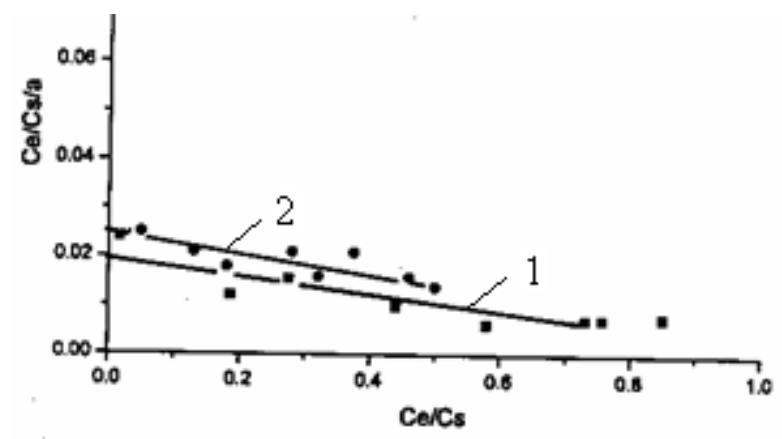

Fig.4. Adsorption isotherm of $\mathrm{NH}_{4}^{+}$and $\mathrm{NH}_{3}$ from aqueous solutions on intact CAN-7 (1) and CANO-7+ Co ${ }^{2+}$ (2) in the coordinates of DS-1 equation.

The adsorption value $\left(a_{m}\right)$ on intact CAN-7 is about $50 \mathrm{mmol} / \mathrm{g}$ and on CANO-7+ $\mathrm{Co}^{2+}$ is $66 \mathrm{mmol} / \mathrm{g}$. Considering this supposition, the result of the present investigation must be taken into account as a possibility of purifying the water containing ammonia ions and ammonium in significant quantities.

\section{Conclusions}

1. It was established that at high $\mathrm{pH}$ values $(10,6)$, the value of $\mathrm{NH}_{4}^{+}$and $\mathrm{NH}_{3}$ adsorption increases considerably due to the formation, in the alkaline medium, of ammonium which exhibits a mechanism and adsorption capacity totally different from that of ammonia ions.

2. The possibility of water purifying from ammonia ions utilizing activated carbon, oxidized and impregnated with $\mathrm{Co}^{2+}, \mathrm{Ni}^{2+}$ and $\mathrm{Cu}^{2+}$ ions, has been found.

\section{References}

[1] Ereeman E., Sieminiewska T., Marsh H, Rand B. Carbon. 1970, 8, p.7-17.

[2] Kaneko K., Nakahigashi Y. Nagata K. Carbon. 1988, 26, p. 327-332.

[3] Kaneko K., Kakei K./ J.Colloid Int. Sci. 1989, 129, p. 583-587.

[4] Tanada H., Tsutsui S., Boki K., Nakamura T. Chem. Express. 1987, 2, p.527-530.

[5] Tamon H.,Okayaki M. Carbon. 1996, 34, p.741-746.

[6] Follin S.,Goetz V.,Guillot A. Ind.Eng.Chem.Res. 1996, 35, p.2632-2639.

[7] Park S.J.,Kim K.D. J.Colloid Int. Sci. 1999, 212, p.186-189.

[8] Lee W.H., Reucroft P.J. Carbon. 1999 37, p. 21-26.

[9] Helminen J. Helenius J., Paotero E.J. Chem.Eng.Data 2001,46, p.391-399.

[10] Domingo-Garcia M., Lopez-Garson F.J., Perez-Mendoza M.J. J Colloid Int.Sci. 2002, 248, p.116-122.

[11] Xie F., Phillips J. Silvia F., Palma M.C., Monedez C. Carbon 200,38,p.691-700.

[12] Domingo-Garcia M., Groszek A.J., Lopez-Garson F.J., Perez-Mendoza M.J. Appl.Catal. A. 2002,233, p.141150.

[13] Stoeckly F.,Guillot A., Slasli A.M. Carbon, 2004, 42, p.1619-1624.

[14] Soto-Garrido G., Groswel Aquilar, Rafael Garcia, Renan Arriagada. J.Chil.Chem.Soc. 2003,v.48, 3. Concepcion 2003 ISSN 0717-9324.

[15] Novikov I.A.,Lastochikina K.O.,Boldina Z.N. “ Methods for identifyng harmful substances in water reservoirs. Moscow. Medicine. 1981. 376p.

[16] Lurie Iu.Iu. Guide to Analytical Chemistry. Publishing house. "Chemistry” M. 1971. p.255.

[17] Zawadzki Jerzy. Infrared Spectroscopy in Surface Chemistry of Carbons. Edited by Peter A. Thrower Marcel Dekkerr. JNC. New York and Basel. 1989. v.21, p.290.

[18] Stekly F. Reviews. Dubinin 's theory of pores volumetric filling and its contribution to the adsorotion science. Proceedings of the Academy of Sciences, chemical series. 2001, № 12, pp. 2163-2170. 